\title{
SLEEP QUALITY AND QUALITY OF LIFE AMONG MALAYSIAN PHARMACY UNDERGRADUATE STUDENTS
}

\author{
NURUL NAJIHAH MOHAMAD HANAPI, SIEW CHIN ONG, GUAT SEE OOI, \\ NUR AIZATI ATHIRAH DAUD* \\ School of Pharmaceutical Sciences, Universiti Sains Malaysia, Pulau Pinang, Malaysia
}

Published online: 24 May 2021

To cite this article: NURUL NAJIHAH MOHAMAD HANAPI, SIEW CHIN ONG, GUAT SEE OOI \& NUR AIZATI ATHIRAH DAUD (2021) Sleep quality and quality of life among Malaysian pharmacy undergraduate students, Malaysian Journal of Pharmaceutical Sciences, 19(1): 65-75, https://doi.org/10.21315/mjps2021.19.1.5

To link to this article: https://doi.org/10.21315/mjps2021.19.1.5

\begin{abstract}
University students tend to have poor sleeping pattern, especially those who took professional courses. Poor sleep quality may affect one's mental and physical wellbeing and quality of life (QoL). Thus, this study aims to determine the sleep quality of pharmacy students, factors associated with it, and their QoL. A cross-sectional study was conducted using questionnaires involving undergraduate pharmacy students in Universiti Sains Malaysia. The Pittsburgh Sleeping Quality Index (PSQI) was used to determine the sleep quality, while QoL was determined using Short Form-36 Survey (SF-36). Poor sleepers were defined as having a PSQI score of $\geq 5$. Independent $t$-test and Chi-square test were used to compare between variables. A total of 256 respondents completed the questionnaires. Majority ( $n=215,84 \%$ ) of the respondents were poor sleepers. Results showed a nearly 3-fold increase in the risk of being a poor sleeper among those taking more than 20 credit units (odds ratio [OR] 2.73; 95\% [confidence interval] Cl: 1.38, 5.39). The mean score for $Q o L$ in seven domains was $61.5 \pm 20.1$. Respondents were shown to have good physical functioning (mean: $87.2 \pm 18.4$ ) but having a low score in the 'energy or fatigue' domain (mean: $47.0 \pm 16.8$ ). One domain in QoL, 'emotional well-being', was found to be significantly lower among respondents with poor sleep $(p=0.035)$. In conclusion, the majority of the respondents had poor sleep quality and a higher credit unit was a factor for poor sleep quality. With regards to QoL, respondents had good physical functioning but poor vitality and sleep quality had affected their emotional well-being.
\end{abstract}

Keywords: Sleeping pattern, Undergraduate pharmacy, PSQI, SF-36

“Corresponding author: aizati@usm.my, aizati.daud@gmail.com

(C) Penerbit Universiti Sains Malaysia, 2021. This work is licensed under the terms of the Creative Commons Attribution (CC BY) (http://creativecommons.org/licenses/by/4.0/). 


\section{INTRODUCTION}

Sleep is a vital component of one's good health and well-being throughout life. Getting enough quality of sleep at the right times can help to protect one's mental and physical health and quality of life (QoL). One of the major problems faced by university students is not having enough sleep (Ansari 2015; Kloss et al. 2011). Students who were taking professional courses, like medicine, pharmacy and dentistry were shown to have been affected by changes in sleep quality as compared to students in other fields (Preišegolavičiūtè, Leskauskas and Adomaitienè 2010; Almojali et al. 2017).

Professional courses have a high academic workload with more credit units, which can cause a high level of stress among students. One study in Iran involving 378 students reported that pharmacy students were shown to have a higher prevalence $(70.6 \%)$ of stress as compared to medical and dentistry students, $66.1 \%$ and $62.5 \%$, respectively (Sharifirad et al. 2012). Another study among pharmacy students showed that most of them sleep less especially on nights before examinations (Zeek et al. 2015). Night reading habit among pharmacy students was previously shown to cause reduced hours of sleep, which subsequently affect the sleep quality (Adeosun et al. 2008).

Poor sleep quality may affect students' cognitive function. Referring to a study conducted in Italy on Year 3 nursing students, those with poor sleep quality were having unsatisfactory academic progress (odds ratio [OR] 2.1; 95\% confidence interval [Cl]: 1.2 , 3.6) (Angelone et al. 2011). In Saudi Arabia, medical students with abnormal sleeping habits tend to get lower academic achievement compared to those who have better sleeping habits (Abdulghani et al. 2012). Among pharmacy students, $57.7 \%(n=253)$ of poor sleepers were associated with the lowest grade point average (GPA) range of 2.00 to 2.99 (Cates et al. 2015).

Sleep quality may also affect the QoL. QoL is an important measure of the impact of illnesses, health changes and mental health status while meeting life satisfaction, emotional well-being and an individual's social life (Andre, Pierre and McAndrew 2017). Several studies showed that there is a significant correlation between sleeping quality and QoL, especially among medical students (Henning et al. 2012; Preišegolavičiūtè, Leskauskas and Adomaitienè 2010; Rezaei et al. 2017). Although it was reported that pharmacy students tend to have poor sleep quality, limited studies were done to identify the factors leading to this condition and the effect of poor sleep quality on their QoL. This data is important for the lecturers to know the general status of the well-being of these students. It may also guide them in providing the appropriate number of tasks during learning activities. Therefore, this study aimed to determine sleep quality among pharmacy students, its associated factors, and the association between sleep quality and QoL.

\section{MATERIALS AND METHODS}

This cross-sectional study involved Year 1 to Year 4 students of the School of Pharmaceutical Sciences, Universiti Sains Malaysia in the academic session 2019/2020. All undergraduate pharmacy students who were able to read and understand English were included in the study, while those who have a history of mental health disorders were excluded from the analysis. With a population size of 459 students, the minimum sample size needed to achieve a significant result of $95 \% \mathrm{Cl}$ with $5 \%$ of margin error is 210 . Ethical approval to perform this study was obtained from the School of Pharmaceutical Sciences, Universiti Sains Malaysia-Hospital Lam Wah Ee Research Ethics Committee.

Malay J Pharm Sci, Vol. 19, No. 1 (2021): 65-75 
Data was collected using a set of questionnaires in English language. The questionnaires consisted of four sections: (i) demographics; (ii) study-related parameters; (iii) sleep quality and (iv) QoL. Demographic information includes age, gender and year of study. Study-related characteristics include the year of study, age, place of staying, credit unit in the current semester and working status.

Sleep quality was measured using Pittsburgh Sleep Quality Index (PSQI). PSQI consists of a total of 18 questions which were combined into seven components scale: subjective sleep quality, sleep latency, sleep duration, sleep efficiency, sleep disturbances (sleep problems), use of sleeping medication and daytime dysfunction (sleepiness). Most questions in PSQI used a 4-point Likert scale and several short answer questions. Sum score ranged from 0 to 21 of global PSQI score, with a higher score indicates worse sleeping quality. Good sleepers were categorised as PSQI global score $<5$ and poor sleepers were those with PSQI global score $\geq 5$ (Carole 2012).

QoL was assessed using SF-36 health survey questionnaire (36-Item Short Form Survey from The RAND Medical Outcomes Study 2019) (Rand.org 2020). SF-36 was designed to measure general health status and it was also shown to be sensitive to changes in sleeping quality (Smith and Shneerson 1995). It measures QoL based on eight scales: (i) physical functioning; (ii) role limitation due to physical health; (iii) role limitation due to emotional problems; (iv) energy/fatigue; (v) emotional well-being; (vi) social functioning; (vii) pain and (viii) general health perception. The percentage of the average score was calculated by adding all the items based on their scale classification and dividing it by the number of items used. A higher score denotes a better QoL.

Continuous variables were expressed as mean \pm standard deviation (SD). An independent $t$-test was used to compare the continuous variables between two groups and a Chi-square test was used for categorical variables. Variables with a significant $p$-value $(<0.05)$ were further tested with logistic regression for association analysis and reported as OR with $95 \% \mathrm{Cl}$. Analyses were performed using SPSS Statistics, Version 22 (IBM Corporation, Armonk, NY, USA).

\section{RESULTS}

A total of 256 respondents completed the questionnaires, with a mean age of $20.5 \pm$ 1.1 years old (ranged 18-23 years old). More than $60 \%(n=170,66.4 \%)$ of the students were taking more than 20 credit units in the current semester and majority of the students $(n=231,90.2 \%)$ were staying in campus (Table 1). Most students $(65.2 \%)$ were reported to spend less than 5 hours per week on an extracurricular activity. Four students had chronic diseases $(1.6 \%)$, while eight students were doing part-time jobs $(3.1 \%)$. 
Table 1: Sleep quality of respondents according to demographic profile and study-related characteristics.

\begin{tabular}{|c|c|c|c|c|}
\hline \multirow{3}{*}{ Variables } & \multicolumn{3}{|c|}{ Number of students, $\boldsymbol{n}(\%)$} & \multirow{3}{*}{$p$-value } \\
\hline & $N$ & $\begin{array}{c}\text { Good sleep quality } \\
\text { (PSQI score }<5 \text { ) }\end{array}$ & $\begin{array}{l}\text { Poor sleep quality } \\
\text { (PSQI score } \geq 5 \text { ) }\end{array}$ & \\
\hline & 256 & $n=41$ & $n=215$ & \\
\hline \multicolumn{5}{|l|}{ Year of study } \\
\hline Year 1 & 65 & $4(9.8)$ & $61(28.4)$ & \multirow{4}{*}{0.004} \\
\hline Year 2 & 63 & $8(19.5)$ & $55(25.6)$ & \\
\hline Year 3 & 71 & $12(29.3)$ & $59(27.4)$ & \\
\hline Year 4 & 57 & $17(41.5)$ & $40(18.6)$ & \\
\hline \multicolumn{5}{|l|}{ Number of credit unit } \\
\hline$\leq 15$ units & 42 & $10(24.4)$ & $32(14.9)$ & \multirow{3}{*}{0.011} \\
\hline $16-19$ units & 44 & $12(29.3)$ & $32(14.9)$ & \\
\hline$\geq 20$ units & 170 & $19(46.3)$ & $151(70.2)$ & \\
\hline \multicolumn{5}{|l|}{ Living situation } \\
\hline Living outside college & 25 & $4(9.6)$ & $21(9.8)$ & \multirow{2}{*}{$1.0^{*}$} \\
\hline Living inside college & 231 & $37(90.2)$ & $194(90.2)$ & \\
\hline \multicolumn{5}{|l|}{ Have roommates } \\
\hline Yes & 239 & $40(97.6)$ & $199(92.6)$ & \multirow{2}{*}{$0.324^{*}$} \\
\hline No & 17 & $1(2.4)$ & $16(7.4)$ & \\
\hline \multicolumn{5}{|l|}{ Have chronic disease } \\
\hline Yes & 4 & 0 & $4(1.9)$ & \multirow{2}{*}{$1.0^{*}$} \\
\hline No & 252 & $41(100)$ & $211(98.1)$ & \\
\hline \multicolumn{5}{|l|}{$\begin{array}{l}\text { Hours/week spent for } \\
\text { extracurricular activity }\end{array}$} \\
\hline$<5$ hours/week & 167 & $30(73.2)$ & $137(63.7)$ & \multirow{4}{*}{0.146} \\
\hline 5-10 hours/week & 71 & $8(19.5)$ & $63(29.3)$ & \\
\hline 11-15 hours/week & 9 & $3(7.3)$ & $6(2.8)$ & \\
\hline$\geq 16$ hours/week & 9 & 0 & $9(4.2)$ & \\
\hline
\end{tabular}

Notes: *Extracurricular activity includes non-academia related activities such as student organisation, sports and club activities; *Fischer's exact test

\section{Sleep Quality and Its Associated Factors}

The mean PSQI global score among respondents was $7.6 \pm 3.3$ (Figure 1), indicating a poor sleep quality on average. Majority of them $(n=215,84 \%)$ had a PSQI global score of $\geq 5$. Year 3 students scored the highest mean score in PSQI global score $8.1 \pm 3.6$ as compared to respondents from other batches $(p=0.004)$. Respondents who were taking 20 credit units or more tend to have poor sleep quality $(70.2 \%$ versus $14.9 \%$ for other categories, $p=0.011$ ) (Table 1). All four students who had chronic diseases and six out of eight students who did part-time jobs were poor sleepers. More than half of the respondents 


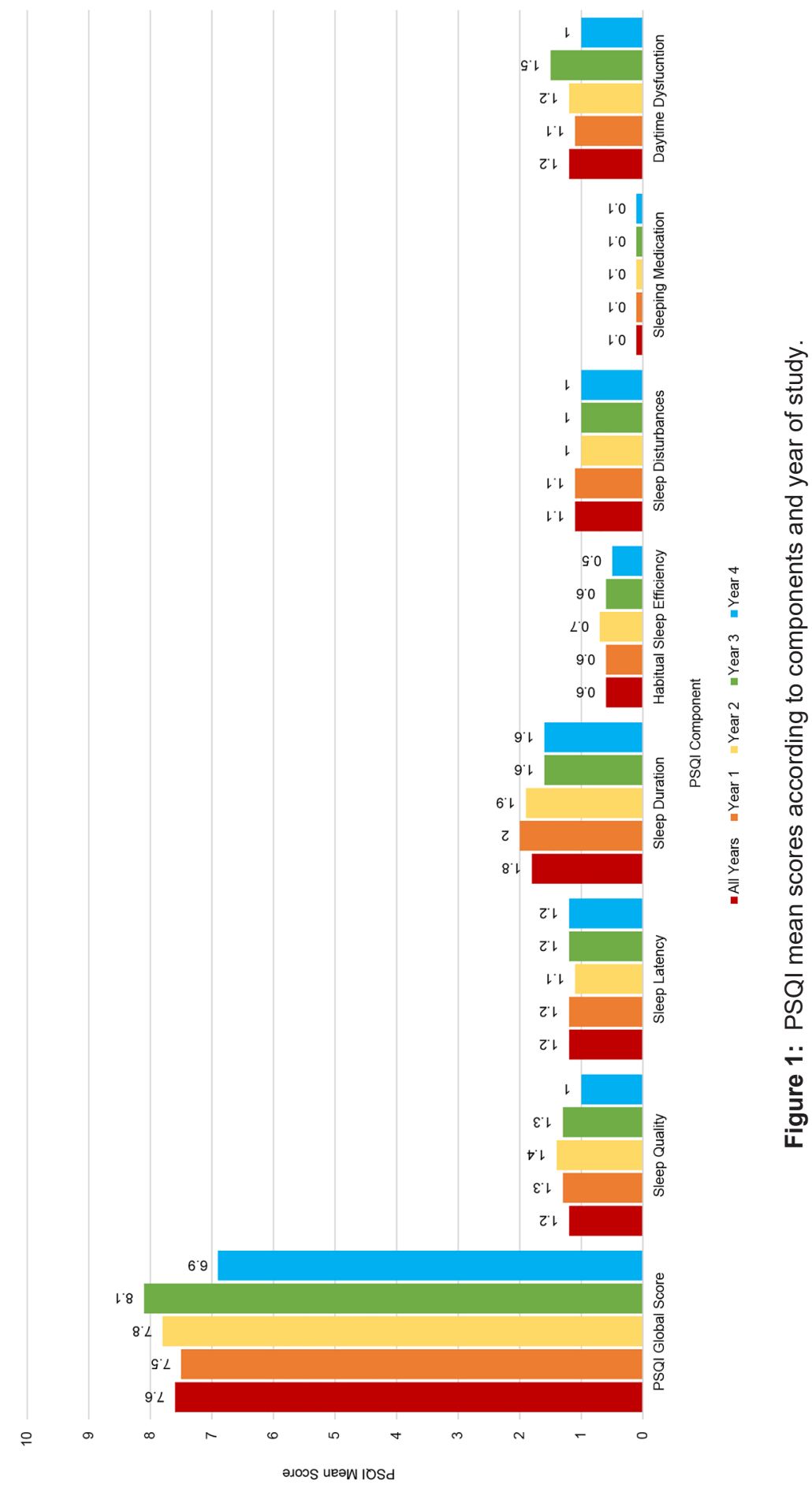

Malay J Pharm Sci, Vol. 19, No. 1 (2021): 65-75 
( $n=150,58.6 \%)$ had slept for $5-6$ hours every night, $17.6 \%(n=45)$ had slept between 6 hours and 7 hours, while $14.5 \%(n=37)$ were reported to sleep less than 5 hours every night.

Univariate logistic regression was performed for variables of batch year and the number of credit units. Comparing between Year 3 and other batches, no significant increase was found in the risk of having poor sleep quality. However, we found a significant increase in nearly 3 -fold on the risk of being a poor sleeper among those taking more than 20 credit units (OR 2.73; 95\% Cl: 1.38; 5.39; $p=0.004$ ).

\section{Quality of Life and Its Association with Sleep Quality}

The mean score for QoL among all respondents was $61.5 \pm 20.1$ (Figure 2). 'Physical functioning' domain showed the highest score among all domains in SF-36, while domain 'Energy or fatigue' showed the lowest mean score (87.2 $\pm 18.4,47.0 \pm 16.8$, respectively) (Table 2). The average mean score in all SF-36 domains was lower among respondents with poor sleep quality as compared to those with good sleep quality, although not significant $(p=0.279)$. Only one domain, 'emotional well-being', was found to be significantly different between respondents with good and poor sleep quality; those with poor sleep quality had a lower score $(62.1 \pm 22.8$ versus $59.0 \pm 18.2, p=0.035)$.

Table 2: Comparison of mean QoL scores ( \pm SD) between good and poor sleepers.

\begin{tabular}{lcccc}
\hline & $\begin{array}{c}\text { All participants } \\
(\boldsymbol{N}=\mathbf{2 5 6 )}\end{array}$ & $\begin{array}{c}\text { Good sleep } \\
\text { quality } \\
(\boldsymbol{n}=\mathbf{4 1})\end{array}$ & $\begin{array}{c}\text { Poor sleep } \\
\text { quality } \\
(\boldsymbol{n}=\mathbf{2 1 5})\end{array}$ & $\boldsymbol{p}$-value \\
\hline General health & $61.5 \pm 20.1$ & $66.3 \pm 17.6$ & $60.6 \pm 20.5$ & 0.279 \\
$\begin{array}{l}\text { Physical functioning } \\
\begin{array}{l}\text { Role of limitation due } \\
\text { to physical health }\end{array}\end{array}$ & $87.2 \pm 18.4$ & $90.1 \pm 13.9$ & $86.7 \pm 19.1$ & 0.112 \\
$\begin{array}{l}\text { Role of limitation due } \\
\text { to emotional problem }\end{array}$ & $59.2 \pm 38.8$ & $72.0 \pm 37.2$ & $62.7 \pm 39.0$ & 0.420 \\
$\begin{array}{l}\text { Energy or fatigue } \\
\text { Emotional well being }\end{array}$ & $47.0 \pm 16.8$ & $49.8 \pm 18.0$ & $47.0 \pm 16.8$ & 0.523 \\
Social functioning & $59.5 \pm 19.0$ & $62.1 \pm 22.8$ & $59.0 \pm 18.2$ & 0.035 \\
Pain & $69.6 \pm 20.3$ & $72.9 \pm 20.0$ & $69.0 \pm 20.4$ & 0.901 \\
Health change & $73.2 \pm 22.2$ & $76.5 \pm 21.7$ & $72.6 \pm 22.3$ & 0.992 \\
\hline
\end{tabular}

\section{DISCUSSION}

Adults require at least 7 hours for a normal sleeping hour per day, as recommended by The American Academy of Sleep Medicine and Sleep Research Society (Watson et al. 2015). We found that more than half of the respondents (59\%) slept between 5 hours and 6 hours per night. Answering the objective of our study, it has been shown that majority of respondents $(84 \%)$ suffer from poor sleep quality, with $7.6( \pm 3.3)$ of the mean global score. Our result was comparable to previous studies conducted among students in health professional courses (Adeosun et al. 2008; Ibrahim et al. 2017). 


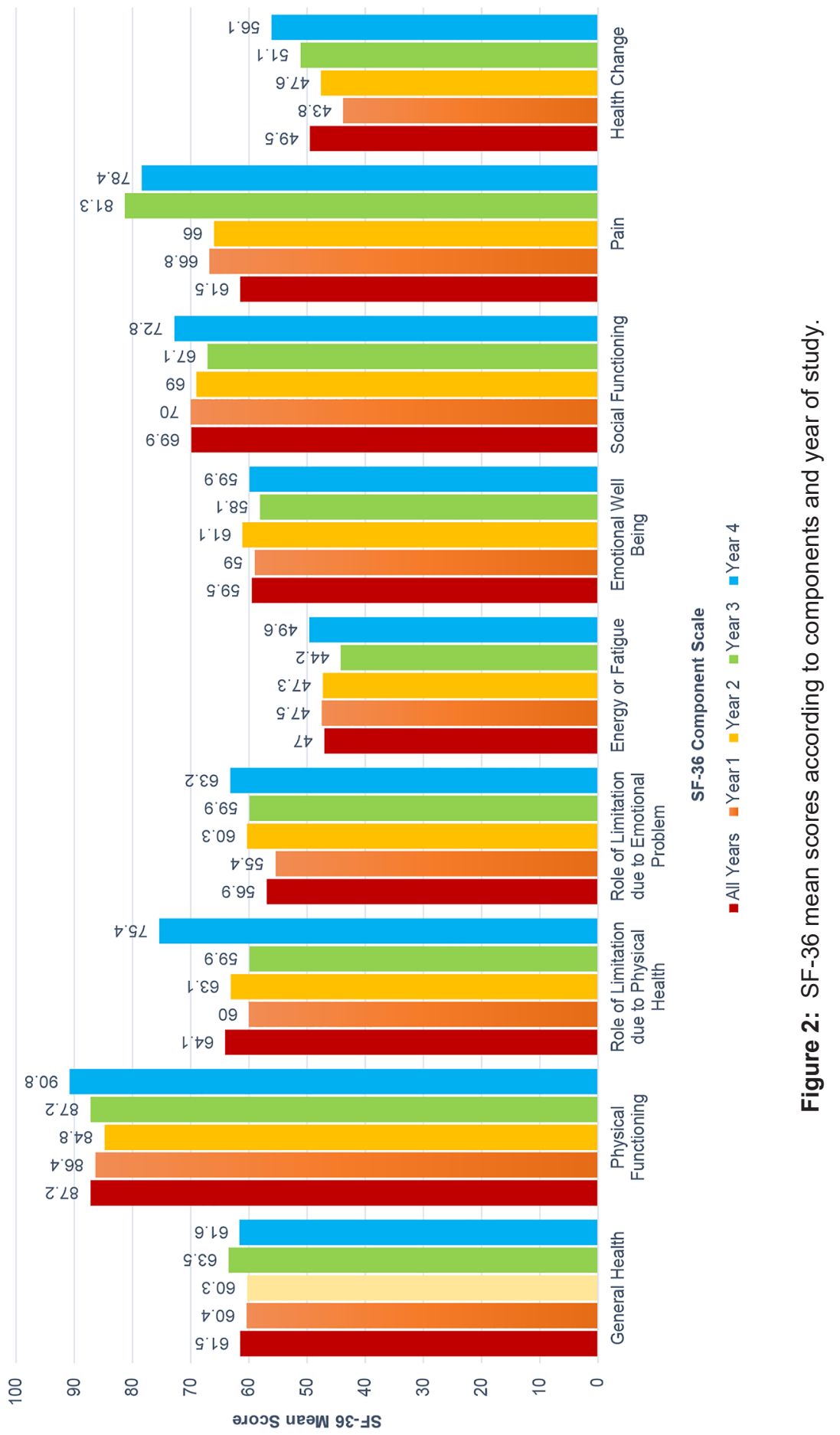

Malay J Pharm Sci, Vol. 19, No. 1 (2021): 65-75 
Two factors were found to significantly affecting sleep quality among our respondents, which are the batch year and number of credit units. First, each year of study carries a different workload throughout the semester. Comparisons among the year of the study revealed that there was a significant difference in sleeping quality between years of study $(p=0.004)$. Year 3 students showed the highest mean score of global PSQI 8.1 $( \pm 3.6)$; which was expected because of the higher burden in terms of assignments and practical hours in the academic batch year (Cates et al. 2015). However, the association was not found to be significant in a univariate logistic regression.

Second, our results showed that students taking more than 20 credit units were prone to be poor sleepers, with an increased risk of nearly 3-fold as compared to those with lower credit units. Professional courses tend to have more credit units per semester as compared to other courses, and it may cause an increase in stress level which subsequently affect sleep quality (Assaf 2013; Sharifirad et al. 2012). Moreover, the current study was carried out during the peak semester days, in which respondents were working hard to meet the deadline of assignments submission and preparing for tests.

Our result showed that physical functioning was the highest score from all SF-36 domains, which was comparable to results from previous studies among university students (Pekmezovic et al. 2010; Sulaiman et al. 2013). Physical functioning is explained on the extent of health condition interferes with a variety of activities, including climbing stairs and walking. Our respondents were considered to be physically active, as most of them involved in co-curriculum activities and they regularly walk from their respective hostels to the faculty or other classes held within the campus.

Our study showed that the general health perception among the respondents was at an average of $61.5( \pm 20.1)$. They perceived to be in a good health state, without realising that it was lower than their expectation. A previous study conducted in Jordan among nursing students also presented the same result with the lowest vitality scores (Sulaiman et al. 2013). In the study, in general, respondents with poor sleeping quality scored lower in all domains in QoL measures as compared to those with better sleeping quality. The respondents may have chronic sleep deprivation due to their needs of high academic workload demand, such as clerkship and case study preparation, and also revision for tests.

Emotional well-being is important in maintaining sleep quality and vice versa. Our result showed that respondents with poor sleep quality had a significantly worse emotional well-being as compared to those with good sleep quality. The emotional well-being domain represents the general mood of affect, including depression, anxiety and psychological well-being of students during a week before answering the questionnaires. Few studies did mention the negative association between stress and QoL among pharmacy students (Hirsch et al. 2009; Assaf 2013). Moreover, previous studies involving university students also revealed that individuals with poor sleep quality showed association with high-stress level and low QoL (Taylor \& Bramoweth 2010; Rezaei et al. 2017).

This study had several limitations. First, this is a single centre study involving pharmacy students in one public university; the result may not be generalised to all pharmacy students from other universities. Second, the results may be prone to recall bias since the questionnaires require the students to recall their activity for the past one month.

In conclusion, the majority of the study population have poor sleep quality, which significantly affected by the number of credit units taken by the respondents. The QoL of the respondents was reported to be good in terms of physical functioning, while emotional well-being was shown to be significantly correlated with poor sleep quality. Awareness of sleep quality and a general approach to improving the emotional well-being and mental health state is imperative in addressing these issues among pharmacy undergraduates.

Malay J Pharm Sci, Vol. 19, No. 1 (2021): 65-75 


\section{ACKNOWLEDGEMENTS}

We are grateful for the help of the class representatives in the distribution of the questionnaires and we appreciate the willingness of the respondents for their participation in this study.

\section{REFERENCES}

ABDULGHANI, H., ALROWAIS, N., BIN-SAAD, N., AL-SUBAIE, N., HAJI, A. \& ALHAQWI, A. (2012) Sleep disorder among medical students: Relationship to their academic performance, Medical Teacher, 34(Sup. 1): S37-S41. https://doi.org/10.3109/0142159X.2012.656749

ADEOSUN, S., ASA, S., BABALOLA, O. \& AKANMU, M. (2008) Effects of night-reading on daytime sleepiness, sleep quality and academic performance of undergraduate pharmacy students in Nigeria, Sleep and Biological Rhythms, 6(2): 91-94. https://doi.org/10.1111/ j.1479-8425.2008.00338.x

ALMOJALI, ABDULLAH I., SAMI A. ALMALKI, ALI S. ALOTHMAN, EMAD M. MASUADI, MESHAL K. ALAQEEL. (2017) The prevalence and association of stress with sleep quality among medical students, Journal of Epidemiology and Global Health, 7(3): 169-174. https://doi.org/10.1016/j.jegh.2017.04.005

ANDRE, A., PIERRE, G. C. \& MCANDREW, M. (2017) Quality of life among dental students: A survey study, Journal of Dental Education, 81(10): 1164-1170. https://doi.org/ 10.1111/j.1365-2710.2006.00773.x

ANGElONE, A., MATTEI, A., SBARBATI, M. \& DI ORIO, F. (2011). Prevalence and correlates for self-reported sleep problems among nursing students, Journal of Preventive Medicine and Hygiene, 52(4): 201-208.

ANSARI, M. (2015) Sleeping pattern of medical students preceding viva examination and their performance, Journal of Nepal Medical Association, 53(200): 262-265. https://doi.org/10.31729/jnma.2742

ASSAF, A. (2013) Stress-induced immune-related diseases and health outcomes of pharmacy students: A pilot study, Saudi Pharmaceutical Journal, 21(1): 35-44. https://doi.org/10.1016/j.jsps.2012.02.006

CAROLE, S. (2012) The Pittsburgh Sleep Quality Index (PSQI). Best Practices in Nursing Care to Older Adults, 6.1. https://www.psychdb.com/_media/sleep/2-insomnia-disorder/ the_pittsburgh_sleep_quality_index_psqi.pdf

CATES, M., CLARK, A., WOOLLEY, T. \& SAUNDERS, A. (2015) Sleep quality among pharmacy students, American Journal of Pharmaceutical Education, 79(1): 9. https://doi .org/10.5688/ajpe79109 
HENNING, M., KRÄGELOH, C., HAWKEN, S., ZHAO, Y. \& DOHERTY, I. (2012) The Quality of Life of medical students studying in New Zealand: A comparison with nonmedical students and a general population reference group, Teaching and Learning In Medicine, 24(4): 334-340. https://doi.org/10.1080/10401334.2012.715261

HIRSCH, J., DO, A., HOLLENBACH, K., MANOGUERRA, A. \& ADLER, D. (2009). Students' health-related quality of life across the preclinical pharmacy curriculum, American Journal of Pharmaceutical Education, 73(8): 147. https://doi.org/10.5688/aj7308147

IBRAHIM N. K., BADAWI F. A., MANSOURI Y. M., AINOUSA A. M., JAMBI S. K., FATANI A. N., et al. (2017) Sleep quality among medical students at King Abdulaziz University: A cross-sectional study, Journal of Community Medicine \& Health Education, 07: 561. https://doi.org/10.4172/2161-0711.1000561

KLOSS, J., NASH, C., HORSEY, S. \& TAYLOR, D. (2011) The delivery of behavioral sleep medicine to college students, Journal of Adolescent Health, 48(6): 553-561. https://doi.org/10.1016/j.jadohealth.2010.09.023

PEKMEZOVIC, T., POPOVIC, A., KISIC TEPAVCEVIC, D., GAZIBARA, T. \& PAUNIC, M. (2010) Factors associated with health-related quality of life among Belgrade University students, Quality of Life Research, 20(3): 391-397. https://doi.org/10.1007/s11136-0109754-x

PREIŠEGOLAVIČIŪTĖ, E., LESKAUSKAS, D. \& ADOMAITIENE், V. (2010) Associations of quality of sleep with lifestyle factors and profile of studies among Lithuanian students, Medicina (Kaunas), 46(7): 482. https://doi.org/10.3390/medicina46070070

RAND.ORG. (2020) 36-item short form survey from the RAND medical outcomes study. https://www.rand.org/health-care/surveys_tools/mos/36-item-short-form.html. (17 April 2020).

REZAEI, O., MOKHAYERI, Y., HARONI, J., RASTANI, M., SAYADNASIRI, M., GHISVAND, $\mathrm{H}$., et al. (2017) Association between sleep quality and quality of life among students: A cross sectional study, International Journal of Adolescent Medicine and Health, 32(2). https://doi.org/10.1515/ijamh-2017-0111

SHARIFIRAD, G., MARJANI, A., ABDOLRAHMAN, C., MOSTAFA, Q. \& HOSSEIN, S. (2012). Stress among Isfahan medical sciences students, Journal Research in Medical Sciences, 17(4): 402-406.

SMITH, I. \& SHNEERSON, J. (1995) Is the SF-36 sensitive to sleep disruption? A study in subjects with sleep apnoea, Journal of Sleep Research, 4(3): 183-188. https://doi.org/ 10.1111/j.1365-2869.1995.tb00167.x

SULAIMAN, K., ALGHABEESH, S., JASSEM, H., ABU-SHAHROOR, L. \& ALI, R. (2013). Quality of life (QoL) among university students in Jordan: A descriptive study, Journal of Education and Practice, 4(11). 
TAYLOR, D. \& BRAMOWETH, A. (2010) Patterns and consequences of inadequate sleep in college students: Substance use and motor vehicle accidents, Journal of Adolescent Health, 46(6): 610-612. https://doi.org/10.1016/j.jadohealth.2009.12.010

WATSON, N. F., BADR, M. S., BELENKY G., BLIWISE D. L., BUXTON O. M., BUYSSE D., et al. (2015). Recommended amount of sleep for a healthy adult: A joint consensus statement of the American Academy of Sleep Medicine and Sleep Research Society, Journal of Clinical Sleep Medicine, 11(6): 591-592. https://doi.org/10.5664/jcsm.4758

ZEEK, M., SAVOIE, M., SONG, M., KENNEMUR, L., QIAN, J., JUNGNICKEL, P., et al. (2015). Sleep duration and academic performance among student pharmacists, American Journal of Pharmaceutical Education, 79(5): 63. https://doi.org/10.5688/ajpe79563 